\title{
A Low Cost \& Efficient Robotic Spraying Machine
}

\author{
Anagha Choudhari, Avinash Shrikhande
}

\begin{abstract}
It is well known fact that India is an agricultural country.It is considered as the lifeline of our Country since it provides the most employment and profit to the nation. But the current state of agriculture in India is not is not upto the mark. The farmers and other agriculture related people are suffering a lot. Considering the problems which are faced by the farmers in the agriculture industry which includes physical strains on the body we as engineers need to design a solution to this. We have seen that due to pesticide spraying the farmers face lot of physical as well as respiratory problems. Our solution to this problem includes designing a machine which helps to reduce manual work of farmers and save them from respiratory problems. The machine is a cost effective solution to help the farmers and can be used even by small scale farmers. Thus, this robotic spraying machine will be of great use. There are various pesticide sprayers available in the market. These spraying techniques are very tediousand time consuming. Purpose is to make an affordable pesticide spraying machine to boost the income of farmers the productivity of crops must be increased. Hence the design tries to improve the pesticide spraying techniques. Through this paper, a real life solution to link agriculture with technology in order to reduce human efforts \& boost up the total output is suggested. This paper aims at explaining the working ofa low cost \& efficient robotic spraying machine that would be operated by the farmer through remote so that thefarmer is not in direct contact with harmful pesticides. On the command from the remote the spraying action will be controlled. The pesticide sprayer would operate with minimal pollution. The model includes 2 nozzles for spraying purpose along with a DC pump which will help inthe total flow of liquid so that constant spraying will occur.
\end{abstract}

Keywors: Atmega 8 \& 16 microcontroller, DC PumpNozzle, DC Pump, Remote

\section{INTRODUCTION}

Agriculture is the backbone of our nation. So the economic level of our nation is maintained by the production level of agricultural products. It will maintain that there are various types of hybrid seeds and high powered fertilizers are used in that field. The modern agriculture has advanced cultivation equipment that plays a vital role in improving the productivity. In ancient days there were no equipments in agriculture field. But recently there are many innovations that are introduced in the cultivated machines. The machines reduce the effort of the human being. The devices are

Revised Manuscript Received on October 25, 2020.

* Correspondence Author

Mrs. AnaghaChoudhari*, Assistant Professor, Electronics \& Telecommunication Engineringdepartment,Yeshwantrao Chavan College of Engineering, Nagpur, India Email: anagha.choudhari79@bgmail.com

Dr. AvinashShrikhande, Professor, Civil Engineering department, Kavikulguru Institute of Technology \& Science ,Ramtek, Nagpur, India, Email: ansktsr@yahoo.com

(C) The Authors. Published by Blue Eyes Intelligence Engineering and Sciences Publication (BEIESP). This is an open access article under the CC BY-NC-ND license (http://creativecommons.org/licenses/by-nc-nd/4.0/) working under the given power. The power is obtained from both finite and infinite resources. The finite resources are capable to give high power at all the times. But the finite resources are about to be extinct in upcoming days. The infinite resources cannot produce constant power from all the times. The finite resources are mostly utilized in the cultivating machines. The sprayers are working in the source battery. The prposed machine aims to remove the backpack and foot spraying techniques, eliminate the human efforts, decrease labour cost by advancing the spraying method, constant flow of droplets and use of non-conventional sources for charging the batteries.

\section{H. LITERATURE REVIEW / SURVEY}

Before writing any paper or doing any work it is basically essential to research about any topic and literature review provides just that. There are various techniques available in market for spraying. Farmers have been using spraying techniques since ancient time for better production. It is quite difficult for us to mention all those techniques used for pesticide spraying because if you see in our country itself we will find hundreds of techniques available. In India farmers use traditional methods for spraying this includes carrying a tank on their back which contains the pesticide. The idea of creating a robot is always influenced by the controller used in it because a controller always acts as the brain of a robot. And on seeing various controllers and their pros and cons, Atmegsa-8 and Atmega16. [5] have been selected . This is the most popular method used in India and is known to us. In this the tank capacity for the machine is about 15 litres and the arrangement is such that in one hand the farmer carries the nozzle for spraying and uses other hand to pump. [2][4] The basic design of our bot has been influenced by the bot which has been suggested by the one in this paper. Along with this it has been a strong source of motivation to help farmers using robotics. [1] [3] Thus, on the basis of the literature survey, it has been decidedthat the components needed to make this machine, the design and the spraying mechanism would be cost effective too so that even small scale farmers can use it.

\section{WORKING}

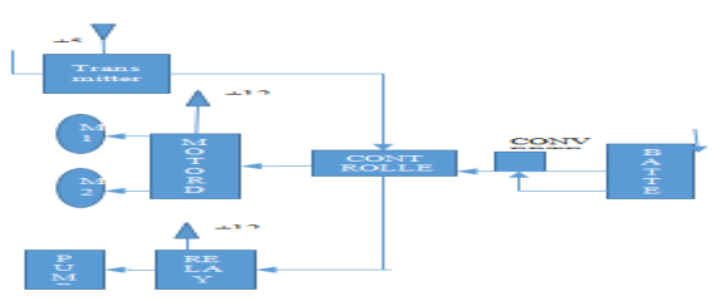

Figure 1: Block diagram of the bot

Published By:

Blue Eyes Intelligence Engineering and Sciences Publication 


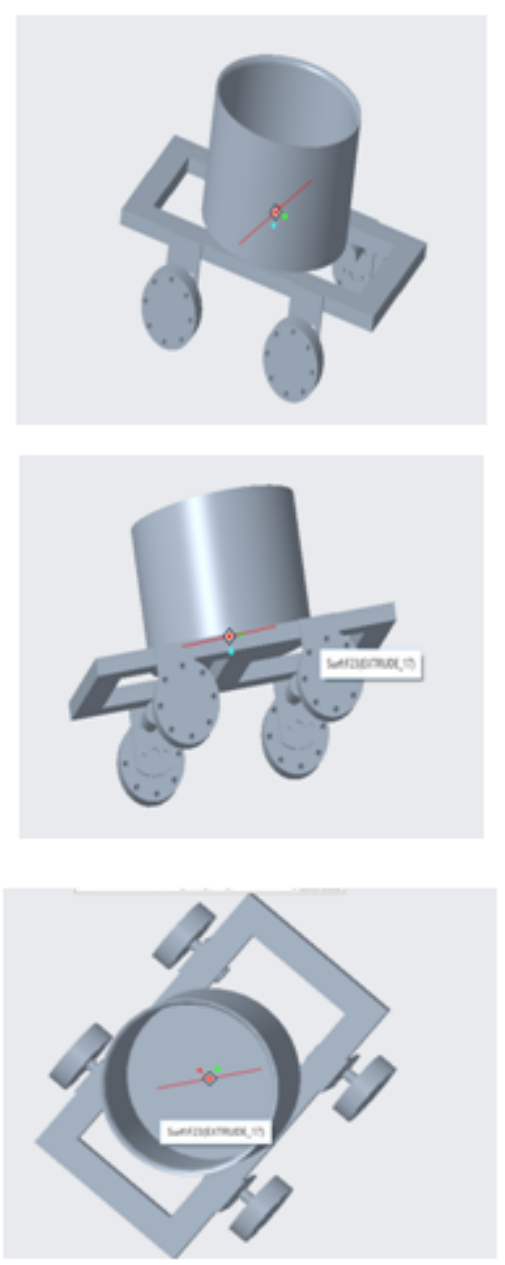

Figure 2: 3-D model of the bot

Hardware and software go hand in hand in today's world and our bot is a mixture of both. The control unit of this machine design contains an ATmega8 microcontroller and ATmega16 microcontroller, a $\mathrm{HC}-12$ trans-receiver module (RF-module), motor driver. The HC-12 module is basically interfaced to create a channel of communication which will carry the function of both transmission and reception of data. The user can give instructions to the Bot which is connected through RF remote using $\mathrm{HC}-12$ (RF module). The instruction is sent in the form of an array of strings and then it is given to the RF module, the module will first decode the message sent by the user, and the received message will then be sent to the microcontroller attached to it. Also, instructions are fed to the motor driver beforehand that on each command which can be received by the RF module the motors will function as per the required instruction. All this process will be completed by the RF module and then the robot will act accordingly. Motor driver or Motor Driver module which allows DC motor to drive on either direction will be used. Two DC motors which will be used to operate 4 wheels of the machine simultaneously in any direction (If in future if more power is required to drive the bot then more number of motors as per required specifications along with another motor driver module can be added). Two DC motors can be controlled with a single motor driver module. Two switches are used in the circuit, one is to ON-OFF the circuit and the other one is to reset. Along with that in the RF remote there will be 5 keys which will decide in which direction we need to move the bot. 4 buttons are used for moving bot in 4 directions and the 5 th button is for switching the sprinkler on and off.

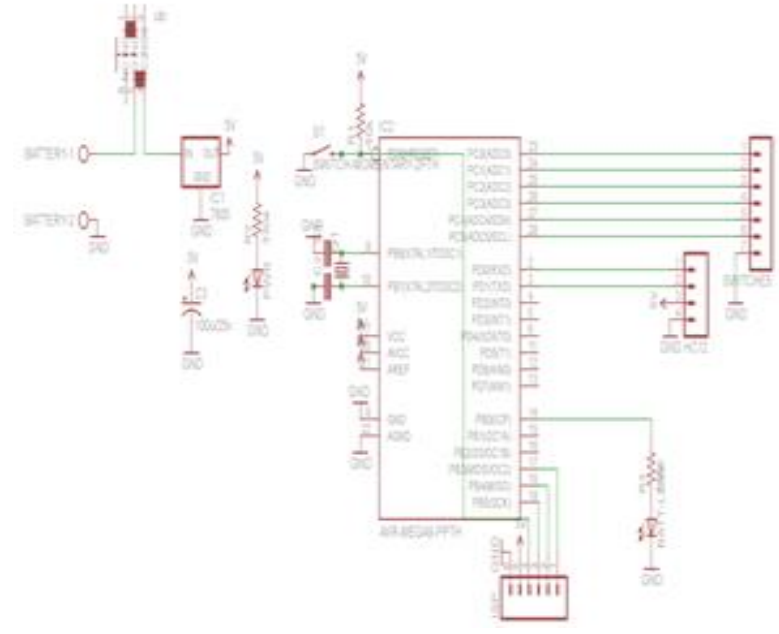

Figure 3:Transmitter side schmatic
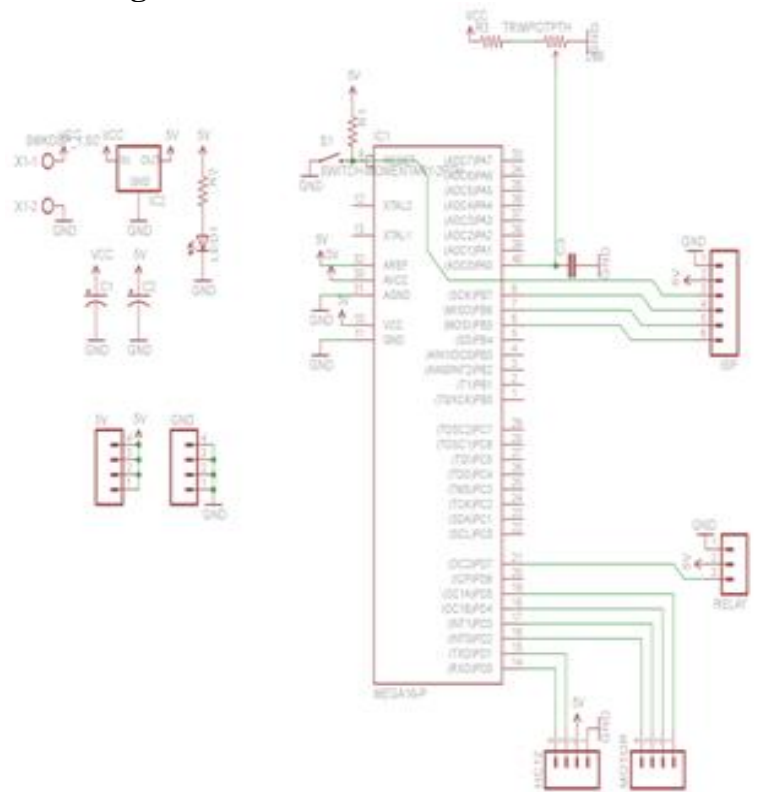

Figure 4: Receiver schmatic

\section{MAJOR COMPONENTS USED:-}

\section{A. ATMEGA 8 \& ATMEGA 16 Microcontrollers:}

ATMega 8 \&16 are the cheapest and most used microcontrollers. ATMEGA-16 is closest to the ATmega328P but it is smaller in memory size and larger in pins. ATMEL designed ATMega16 by using RSIC CPU and 8-bit CMOS technology which helps it to operate with other TTL/CMOS devices by consuming less power. Its internal structure allows the designer to use the sleep mode, power vs performance methods to use it efficiently by consuming less power. Same is the case with ATMEGA-8 microcontroller too. In the bot, ATMEGA 8 is used in the transmitter side whereas ATMEGA 16 is used in the receiver side.

\section{B. DC MOTOR:}

A DC motor is any of a class of rotary electrical machines that converts direct current electrical energy into mechanical energy. The most common types rely on the forces produced by magnetic fields.

\section{Published By:}

Blue Eyes Intelligence Engineering and Sciences Publication

(c) Convriaht: All riahts reserved.

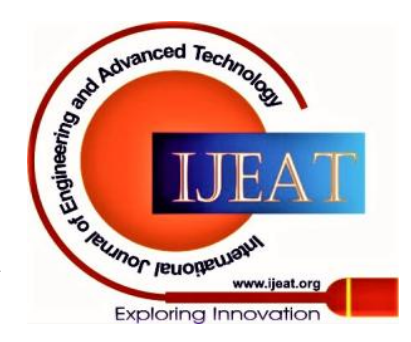


Nearly all types of DC motors have some internal mechanism, either electromechanical or electronic; to periodically change the direction of current flow in part of the motor.

\section{NOZZLE:}

Nozzle is the basic component of the spray pump which generate spray pattern. The nozzle is selected as per the study. It decides how much area of the plant should cover. Generally brass, stainless steel, tungsten carbide, ceramic are used to manufacturing the nozzles. In this the brass is cheapest one but the main problem is that its corrosion resistance is less than that of the steel. Also, corrosion takes place in it due to the liquid fertilizers. As it is having such kind of drawba:

cks the material which is good enough is Stainless steel. It gives longer performance and produces an uniform pattern of spray .so that we had selected stainless steel material for nozzle.

Nozzle flow rate:-The flow rate through the nozzle varies with orifice tip size and nozzle pressure. Installing nozzles with a larger or smaller orifice size is the most effective way to change the sprayers output. Changes in nozzle pressure can also be used to increase or decrease sprayer output, but not as significantly as changes in orifice size. Pressure must be increased four times to double nozzle flow rate.

Nozzle Spray Patterns:-Hollow cone and solid cone-nozzles produce a circular pattern. Hollow cone nozzles generally make finer, smaller particles than the solid cone. These nozzles are used on handgun sprayers and row crop sprayers.

Nozzles are used to broadcast most types of pesticides. The pattern is fan shaped with gradually tapered edges. Uniform coverage across the sprayer width is achieved by overlapping the tapered portion of the pattern. This is also a common spray pattern used for applying structural pesticides to floor or wall surfaces.

\section{RELAYS:}

A relay is an electromagnetic switch operated by a relatively small electric current that can turn on or off a much larger electric current. The heart of a relay is an electromagnet.

\section{E. HC-12 TRANS-RECEIVER MODULE (RF-MODULE) :}

.This module offers a wireless data transmission and reception range of approximately $1 \mathrm{Km}$ in open air. It's a low power radio chip which is ultra easy to use. This module has an onboard STM8S003F3P6 MCU which is communicating with the SI4463 so that the user can communicate with the module using a simple TTL 2 wire serial interface (RX, TX, GND).

\section{F. PUMP:}

A pump is a device that moves fluids (liquids or gases), or sometimes slurries, by mechanical action. . Pumps operate via many energy sources, including manual operation, electricity, engines, or wind power, come in many sizes, from microscopic for use in medical applications to large industrial pumps.

\section{G. 7805 VOLTAGE REGULATOR IC:}

The voltage source in a circuit may have fluctuations and would not give the fixed voltage output. The voltage regulator IC maintains the output voltage at a constant value 7805 provides $+5 \mathrm{~V}$ regulated power supply.

\section{H. RECHARGEABLE BATTERY:}

. It comprises one or more electrochemical cells, and is a type of energy accumulator used for electrochemical energy storage. It is also known as a secondary cell because its electrochemical reactions are electrically reversible. Rechargeable batteries come in many different shapes and sizes, ranging from button cells to megawatt systems connected to stabilize and electrical distribution network. Several different combinations of chemicals are commonly used, including lead acid, nickel cadmium, nickel metal hydride, lithium ion, and lithium ion polymer.

\section{SWITCH:}

A network switch (also called switching hub, bridging hub, officially MAC bridge)is networking hardware that connects devices on a computer network by using packet switching to receive and forward data to the destination device that needs it..

\section{J. MONSTER MOTOR DRIVER:}

The Dual Monster Moto Shield VNH2SP30 DC Motor Driver 2x14A (Peak 30A) is essentially a ramped up version of our Ardumoto motor driver shield. For this Monster Moto Shield, It is replaced the L298 H-bridge with a pair of VNH2SP30 full-bridge motor drivers. It is also beefed up the support circuitry so this board is capable of driving a pair of high-current motors! The VIN and motor out are pitched for our $5 \mathrm{~mm}$ screw terminals (not included), making it easy to connect larger gauge wires.

\section{RESULT}

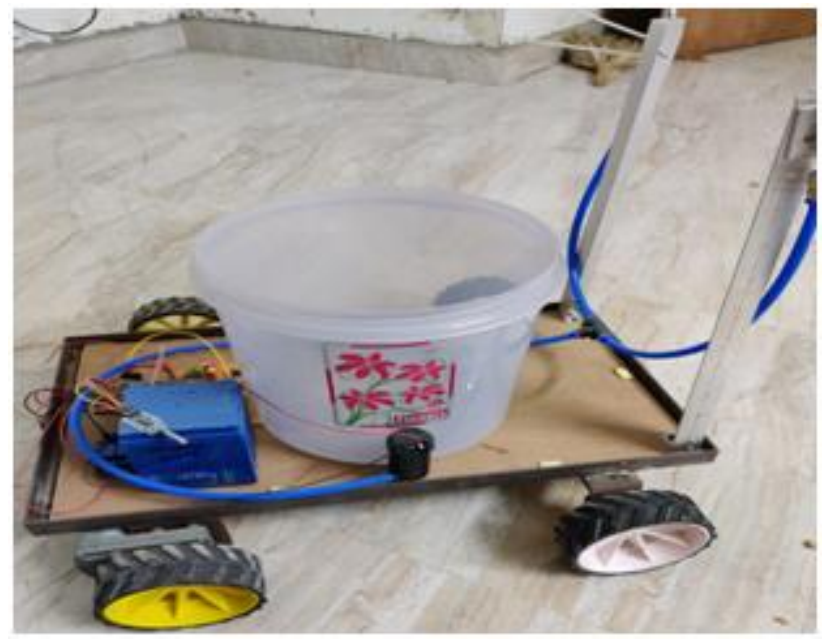

Figure 5: Final Structure of the bot

As the command is given from the transmitter side the bot will move accordingly with the help of battery provided in the bot. The operator is at some distance from the bot so the chance of harmful effects on health is reduced. In addition, the spraying is uniform due to the special nozzles utilised. Also the cost is very less.

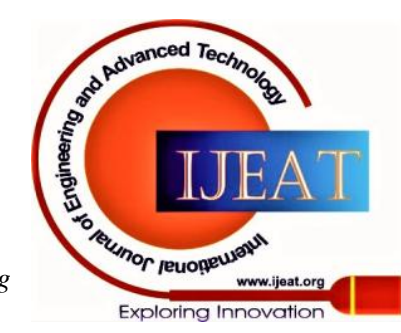




\section{CONCLUSION}

Thus the proposed bot provides a cost effective and safe alternative for the farmers cultivating medium heighted crops like cotton, rice, wheat etc. and vegetables like tomatoes, cauliflower,etc..Following conclusions can be drawn from the bot :

- It has been observed that the current method used for spraying includes carrying the spraying machine on back results in various health issues like back pain \& the poisonous fumes of the pesticide may cause respiratory disorders for the worker.

- Sothe proposed design of the bot seems to be the alternative solution for above mentioned problems.

- Also upon comparing the bot with other commercially available ones in the market, it proves to be more advantageous in terms of efficiency, safety, spraying coverage area., etc.

\section{FUTURE SCOPE}

1. The capacity of pesticides that can be carried can be increased if required but for that the motors and batteries also need to be changed equivalently.

2. The height of the sprayer can be adjusted (Upto 1.5m from ground

3. The speed can be increased if required by changing the motors.

\section{REFERENCES}

1. Shailesh Malonde, Shubham Kathwate, Pratik Kolhe, Nishant ingole, Rupesh Khorgade "Design and development of Multipurpose Pesticide Spraying Machine", International journal of Advance Engineering and Global Technology", ISSN No:2309-4893 volume-04, Issue-03,(May-2016). pp:1945-1953

2. RajashekhargoudAngadi, Rohit L G, Satish Changond, Santosh Kagale "Cam Operated Agrochemical Pesticide Sprayer", International journal of Engineering Research \& Technology", ISSN No:2278-0181 volume-06, Issue-01,January-2017, pp: 233-236

3. S R Kulkarni, R V Nyamagoud, Hareesh Naik, Mohan Futane "Fabrication of Portable Foot Operated Agricultural Fertilizers and Pesticides Spraying Pump", International journal of Engineering Research \&Technology”,ISSNNo:2278-0181 volume-04, Issue-07,July-2015, pp:63-69

4. R. D. Fox, R. C. Derksen, "Visual and image system measurement of spray deposits using water-sensitive paper", Applied Engineering in Agriculture Vol. 19(5), pp: 549-552, 2003 American Society of Agricultural Engineers ISSN 0883-8542

5. https://www.elprocus.com/atmega8-microcontroller

\section{AUTHORS PROFILE}

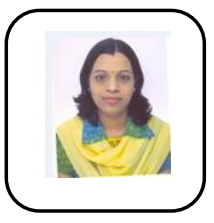

Prof. Mrs. Anagha Choudhariis working as Assistant Professor in Electronics \& Telecommunication Engineering Department of Yeshwantrao Chavan College of Engineering, Nagpur, Maharashtra. Total teaching experience of 16 years. Area of research is Embedded Systems. Total number of publications in conferences \& journals is 15 .

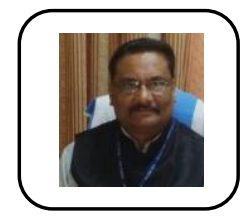

Dr. Avinash Shrikhandeis working as Professor in Civil Engineering Department, Kavikulguru Institute of Technology \& Science, Ramtek,District: Nagpur, Maharashtra. His total teaching experience is 30 years. Area of research is Environmental Engineering. Total number of publications in intnationaljournals \& conferences is 32 .

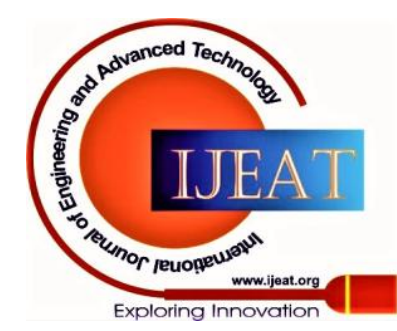

